\title{
Designing a Micro-lecture for the Motivating Phase of Production-oriented Approach in College English Teaching
}

\author{
Qiu-ping Huang \\ College of Foreign Studies, \\ Guilin University of Electronic Technology, \\ Guilin, Guangxi, China \\ 122407609@qq.com
}

\author{
Hua Yang \\ College of Foreign Studies, \\ Guilin University of Electronic Technology, \\ Guilin, Guangxi, China \\ 16898559@qq.com
}

\begin{abstract}
The aim of this study is to prove the feasibility of applying a micro-lecture in motivating of Production-Oriented Approach (POA). This paper presents a brief introduction to the teaching hypothesis and procedure of POA motivating. It also analyzes the micro-lecture's characteristics which are cons is tent with the teaching requirements of POA motivating. Moreover, it studies some specific strategies of design and application of a micro-lecture for POA motivating. The results we obtained demonstrate that a micro-lecture can act as an effective means for POA motivating in College English teaching. The innovation in this paper is mainly embodied in the following two aspects: firstly, we provided evidence from teaching practice to clarify why a micro-lecture can serve as appropriate input materials; secondly, we proposed some practical strategies for designing a micro-lecture.
\end{abstract}

Keywords-a micro-lecture; production-oriented approach; motivating; College English

\section{INTRODUCTION}

"Production-oriented approach" (POA) is the theoretical system established by Professor Wen, an outstanding expert on foreign language teaching in China. The system which contains abundant teaching concepts and teaching hypothesis plays a very practical guiding role for the College English teachers. The teaching procedure of POA includes motivating, enabling and assessing ${ }^{[1]}$. The three steps are dominated by teachers and complement each other during the whole teaching process.

Being different from other teaching approaches, POA puts task-based production motivating at the beginning of each new teaching unit. This is because POA holds the idea that producing can stimulate the students' learning desire and enthusiasm more strongly than the input learning. This paper will focus on the motivating phase of POA and try to explore how to use a micro-lecture as a modern teaching method to realize the production target.

This work is supported by the Foundation projects: (1) Research on the teaching mode of college English 'integrated teaching' from the perspective of the cultivation of international engineering application-oriented talents (Guangxi Higher Education Institution Research Project, 2018); (2) Research on the teaching mode of College English scaffolding writing based on microlectures(2017JGA202)

\section{THE CONNOTATION ANALYSIS OF MOTIVATING}

\section{A. The Teaching Hypothesis of Motivating}

The POA motivating is built on the theoretical basis of the output-driven, input-enabled hypothesis. The theory points out that output are both the motivation of language acquisition and the goal of language learning. Input is the means to achieve the current output task, rather than simply to serve to foster understanding and increase acceptance of knowledge in order to lay the foundation for future language output ${ }^{[2][3]}$. POA motivating aims at making students build up knowledge and skills by accomplishing the assigned tasks in the process of participation, experience, interaction and cooperation.

On the theoretical premise of the production motivating, once the students know exactly the significance of the output task and realize their own language deficiencies, they will become more active and concentrated in the input study to attempt to complete the assigned task. Meanwhile, being provided with guidance input information timely; the students will expand their existed knowledge and language system by adopting some learning strategies. Accordingly, their language output quality will be refined during the process of repeated practice. As a result, smoothly, they will accomplish the given production task and enhance their language cognitive ability.

\section{B. The Teaching Procedure of Motivating}

In the traditional College English classroom, some teachers often arrange lead-in activities before the presentation new knowledge by showing pictures, videos, movie clips, etc. to arouse the students' interest about the learning topics. Although this step may function as a good warm-up for the subsequent learning contents, it ignores presenting a clear output objective to guide the students' learning process. Compared with task-based driving, POA motivating sets a production motivating task at the very beginning of teaching procedure. The motivating task which has clear target and orientation can facilitate students to be aware of their language deficiencies and stimulate their desire to learn and produce.

POA production motivating can be divided into three teaching steps ${ }^{[4]}$. To begin with, the teacher presents communication scenes for a certain topic or theme. Then 
students try to complete the designated communication task. Finally, the teacher explains the teaching objective and the production task. More concretely, motivating is to present communication scenes at the beginning of the new knowledge of each unit aims at driving students to try to produce according to the topic mentioned in the scene. In the process of attempting, students are gradually aware of the inadequacy of their own language or topic content, then experience the awkwardness caused by poor communication. In this procedure, they shape a sense of hunger pangs and strong learning desire. Based on the above-mentioned activities, the teacher sets clear and targeted teaching objectives which conform to the students' cognitive level and help students to be clear about their learning direction.

\section{THE CHARACTERISTICS OF A MICRO-LECTURE ARE APPLICABLE TO MOTIVATING}

The micro-lecture, adopting micro teaching videos as a main carrier, is defined as video curriculum resources focused on the knowledge points or for a teaching step with the characteristic of contextualization and be open to a variety of learning ways ${ }^{[5]}$. David Penrose defines the micro-lecture as knowledge burst ${ }^{[6]}$ and holds the view that it may achieve the same effect with traditional long-time teaching under the support of the corresponding assignments and discussion. Its core idea is to relate the teaching materials with teaching targets to create a highly concentrated learning experience. With the popularization and wide application of mobile technology, a micro-lecture is becoming the motivating approach to promote the realization of POA production task. Compared with the traditional English class, the micro-lecture has some particular characteristics which are consistent with the teaching requirements of POA motivating.

\section{A. With Short and Concise Content}

The video is the main expression form of micro-lecture teaching with the obvious feature of being short and concise. Former studies show that adults' attention can't last too long, otherwise their learning effect will be impaired. Currently, it is widely admitted that the college students are more willing to accept simple, diverse and interesting information, for they grow up in the information technology environment and get used to it . Consequently, it is hard to motivate them by using the traditional college English teaching model. Considering this situation, the teacher should not arrange too much time to motivate in College English teaching practice, because students has limited ability to access to information. Too much materials input will increase the students' cognitive load, and speed them to be easily distracted. The span of micro-lecture is generally controlled in 10 minutes. Its content is usually short and concise, which is suitable for POA motivating.

\section{B. With Clear Theme and Teaching Objectives}

The English teacher usually uses some videos to attract the students' attention and cause their interest in learning while dealing with the warm-up or lead-in activities in traditional College English class. However, it is quite difficult to find the suitable video resources which are relevant with the teaching objectives. To solve this problem, the teacher may make micro-lectures to make up for the deficiency of the traditional ways. In particular, the teacher should be aware of some requirements of making a micro-lecture. To start with, the teaching materials delivered by a micro-lecture should focus on some particular language points. Besides, the design of teaching resources and the arrangement of teaching activities should be based on a specific theme. These requirements are consistent with the core idea of POA, i.e., teaching activities must serve the teaching objectives.

\section{With real communication situation}

A micro-lecture is designed by using a variety of information technology, different ways of input and dynamic images $^{[7]}$ to create micro teaching resources and environments featured as closely combining with the specific teaching activities and the real situation. With a video as the carrier, the micro-lecture integrates the language points into the context. By the way of integrating different expressions, such as pictures, sounds, animation, etc., the micro-lecture vividly presents the knowledge points, restores the real scene of language communication and helps the students learn in that real environment as far as possible. Furthermore, it stimulates the students to take a deep thinking about the given topic. It is conformity with POA concept that the teacher should present communication scenes which have mobility and a certain potential teaching value in the process of motivating.

\section{With Flexible Learning Style}

With the widely application and nearly complete coverage of the network, students can learn the micro-lectures flexibly, which is not limited by learning place and equipment. Students can learn the course resources anytime and anywhere by using various electronic devices, such as computers, mobile phones, etc.. This shift of the learning way is beneficial for all students who have different language levels. Students can set their own learning pace according to their own cognitive level and avoid the negative influence of peer pressure in classroom teaching. Moreover, if the students finish the micro-lecture before class and prepare for the classroom study, then the later stage will facilitate the teaching process to go smoothly.

\section{STRATEgIES FOR THE DESIGN OF A ENGLISH MICRO- LECTURE IN POAMOTIVATING}

As an auxiliary English teaching method, the development of the micro-lecture teaching benefits from the booming of information technology ${ }^{[8]}$. It then spreads through the network. We try to dig out how to design a micro-lecture in College English teaching practice, how to make it become an effective input material in motivating and how to achieve the dual realization of communicative goal and language goal. In general, a micro-lecture design should follow the following principles.

\section{A. To Create Authenticity Situations}

The first strategy is to create authenticity situations based on presetting the communication scenes that students may encounter in the future. The communicative method is an important method in college English teaching. John \& Davies 
pointed out that language is not merely a goal which is primarily a study of grammar and vocabulary features, but it has become a communication tool ${ }^{[9]}$. Under the guidance of this teaching philosophy, college English teaching attaches great importance to the design of communicative tasks with the purpose of stimulating students' communicative needs and constructing communicative language ability actively. This kind of teaching thought accords with the rules of language application. Nevertheless, while observing the College English class, we find that the application of communicative method can't fully stimulate students' active communicative intention. This phenomenon deserves our reflection. The main reason is that the setting of the communicative scene is out of the students' communicative needs; accordingly, it can't inspire and prompt their willingness to communicate proactively.

Therefore, under the guidance of POA teaching idea, the first teaching step of POA motivating is to put forward the real communication scenario. It is the most challenging part which calls for the teacher's teaching tact. The teacher is expected to render the communicative scenes and help students experience the truth of the scenarios. Here is an example for accounting for what a real communicative scene is in our teaching practice. The students are required to introduce Chinese Mid-autumn Festival to a foreigner in English, and then they may come up with the following situations.

- Suppose you have a schoolmate from Britain, then you invite him/her to come to your home and enjoy the holiday. How do you invite him/her?

- Suppose you have a pen pal, and he/she is interested in Chinese traditional festival and keeps asking you some questions about the Mid-autumn Festival. How do you answer him/her?

- Suppose in a supermarket, you meet a foreign tourist who is curious about moon cakes and turns to you. How do you make an explanation?

- Suppose you work in a foreign company, your American boss asks you to work over time for emergency at the mid-autumn festival. How do you say no to your boss?

As an effective motivating method, a micro-lecture can create a real scene of language communication based on topics or themes, which undoubtedly provides great flexibility for college English teaching. The current college English teaching materials cover a lot of themes, involving philosophy, economy, society, history, culture, science and technology, etc. Under the Internet and big data environment, the extensive network resources also offer convenience and possibility for teachers to expand teaching resources. In the process of microlecture designing, the teacher selects the teaching resources to determine the motivating task. But for a few knowledge areas which are rather abstract or far away from the student' life, teachers should take more efforts to create a real teaching situation which is combined with the production task in a micro-lecture.

To achieve the authenticity of the social scenes, the teacher can use a multi-modal teaching mode to maintain flexibility and attraction of the micro-lecture. Meanwhile the teacher need to deeply integrate the existed resources under network data environment, with the updated view and materials to present the communicative scenes ${ }^{[10]}$. However it should be noted that the function of language need to be highlighted all the time even if the technology is prevailing. In real situations, students are likely to experience some embarrassed situations in which they don't know how to express themselves even facing a simple production task. Afterwards, they realize their language communication ability is weak and feel shocked, hence they are willing to identify the production tasks and have the strong desire to acquire more knowledge.

In a word, a micro-lecture can effectively inspire the students' communicative intention and stimulate their production desire through real representation scenes, and finally it can push forward the realization of motivating function in POA English teaching.

\section{B. To Set Challenging Topics}

Followed by creating the real communication scenes, the teacher should set the topics which challenge the students' cognitive ability, taking into account the different levels of the students. The topics should be closely connected with producing motivating tasks. Due to classroom activities being carried out around a specific topic, the students will be guided by a clear teaching target in the process of learning. While probing into the topics, students may come up with the ideas to solve the questions based on their original cognitive structure, integrating the old knowledge with new knowledge. The overall output task set on the basis of the topics should be decomposed into a number of small tasks, so that the students can finish it gradually and then construct their cognitive ability step by step. How does the teacher decompose the overall tasks? Here is an example. The overall task "introduce the steps of making moon cakes in English” can be decomposed into 5 minor tasks.

- Preparing ingredients;

- Making fillings;

- Making covers;

- Shaping the moon cake;

- Baking the moon cake.

Specifically to say, the topic design of a micro-lecture is expected to achieve a specific teaching goal with moderate difficulty ${ }^{[11]}$. What's more, consideration should be given to the students' cognitive ability and language level. Accordingly the topics should be a little challenging so as to stimulate students' learning motivation and desire for producing the motivating task. Namely, the topic can be understood by the students, but its degree of difficulty should be slightly higher than the students' existed language ability. The teacher should carefully design a topic and make it combine with the teaching objective, so as to provide students with enough space for thinking.

At present, due to the large-scale class teaching and different English levels of the students, it is rather hard for the teacher to do the teaching organization in accordance with the students' different aptitude. As a result, the superior students will decrease learning interest because the materials are rather simple. On the other hand, the inferior students can't catch up 
for their weak foundation. Therefore, college English microlecture resources should take the students' cognitive ability level into account and construct multilevel micro-lecture resources. When the production motivating task is rather complex, the motivating tasks should be decomposed and completed by the students' team work. So they may deepen the understanding of assigned topics and improve their English communication skills through diverse thinking modes. In the whole teaching process, the teacher should play a leading role, organizing the students to understand the teaching content thoroughly, and then guide students to choose practical input materials to fulfill the motivating tasks and reach the established teaching goal gradually.

To sum up, the teacher should obey the following rules while setting topics in the Micro-lecture.

- Target the teaching objectives;

- Conform to the students' cognitive ability;

- Suit the students' language level.

\section{To Unite The Informative and Practical Content}

In College English teaching, the content selection of a micro-lecture should be connected with the college English curriculum standard and teaching requirements. It is determined on the basis of analyzing the demand of the production task. The teacher should select both the informative and practical teaching materials. On one hand, the piling of language knowledge will make the students feel bored. On the other hand, only focusing on the practical training of language skills will lead to the lack of systematic knowledge. In general, the teaching content is to serve the purpose of teaching. The more appropriate the content is, the more likely it is to facilitate effective producing activities. Conversely, the effectiveness of the production needn't be discussed at all.

The earliest practitioner, Bergmann \& Sam ${ }^{[12]}$, who applied a micro-lecture into the flipped classroom, pointed out that the teacher should carefully consider whether the micro-lecture can achieve the teaching goal or not before the use of microlecture teaching. Only when the technology is an effective tool to solve the task at hand, it can be used. We can't neglect that some improper video learning materials even do harm to students. In details, the selection of language points still need to conform to the requirement of the course. In simple terms, a micro-lecture should highlight the key points of language learning, and consider the students' learning and professional interest.

In addition, while designing the topics, the teacher should take the psychological characteristics of college students into account. The social hot spot, cultural customs, campus life, etc. may serve as good topics in College English motivating phase, reflecting the individualized teaching. This kind of design will attract students' interest in learning and arouse their motivation to learn English. In short, in the selection of knowledge points and the micro-lecture video production, the essence of knowledge must be expressed. By leaning micro-lectures, the students feel the charm of the English language and communicative value, and then form the motivation to build up their own English knowledge.

\section{SUMmARY}

This paper explains the POA motivating teaching hypothesis and procedure. Then it analyzes the reasons why a micro-lecture can act as an effective method for motivating of POA in College English teaching. Finally it discusses the design principles and strategies of a micro-lecture, such as to create authenticity situation based on presetting the communication situations, to set the topics with cognitive challenging considering the different levels of the students, to combine the informative content with the practical one by selecting the appropriate materials. Only by these ways can a micro-lecture become effective input materials in POA motivating. For the viewpoints proposed in this article, we will try to test them in the future College English teaching practice.

\section{ACKNOWLEDGMENT}

My deepest gratitude goes first and foremost to Prof. Wen, Q. for her vital theoretical framework and system of POA which guides me to do the research. Then I would like to express my heartfelt gratitude to my teammates for their assistance with my College English teaching experiments. They have walked me through all the stages of the writing of this paper.

\section{REFERENCES}

[1] Wen, Q. 2014. Production-oriented approach to teaching Chinese adult learners[R] (In Chinese). A keynote speech at the $7^{\text {th }}$ International Conference on English language Teaching in China. Nanjing, China, October 23-26

[2] Swain, M. 1995. Three functions of output in second language learning[A]. In G. Cook and B. Seidlhofer (eds.). Principles and Practice in Applied Linguistics: Studies in Honor of H. G.Widdowson [C]. Oxford: OUP. 125-144

[3] Krashen, S. 1985. The input hypothesis: Issues and Implications[M] London: Logman.

[4] Wen, Q. 2015. Developing a theoretical system of production- oriented approach in language teaching $[\mathrm{J}]$ (in Chinese). Foreign language teaching and research (bimonthly). Vol.47 No. 4:547-558

[5] Hu Ti-sheng. "micro-course": a new trend in the development of regional education information resources[J] (in Chinese). Technology Enhanced Foreign Language Education, 2011 (10) : 61-65.

[6] Shieh, David. These lectures are gone in 60 seconds. Chronicle of Higher Education, 2009, (26): 1-13

[7] Baker, J.W. 2000. The "Classroom flip": Using web course management tools to become the guide by the side.[R]. Paper presented at the $11^{\text {th }}$ International conference on College Teaching and Learning, Jacksnonville, U.S.

[8] Berrett, D. 2012. How "Flipping" the class room can improve the traditional lecture[J]. Chronicle of Higher Education 58(25):16-18

[9] John, T. F. \& Davies, F. 1983. Text as vehicle of communication: The classroom use of written texts in teaching reading in a foreign language[J]. Reading in a foreign language, (1):1-19

[10] Forsey, M. Low \& D. Glance. 2013. Flipping the sociology classroomTowards a practice of online pedagogy[J].Journal of Sociology 49 (4):471-485

[11] Correa, M. 2015. Flipping the foreign language classroom and critical pedagogies-A (new) old trend [J]. Higher Education for the future.

[12] Jonathan Bergman. Aaron Sam, Bergman, et al. Flipped classroom and MOOCs: an emerging education revolution [M]. Beijing: China youth press, 2015:70-74. 